\title{
The Theory and Development of Business Ecosystems
}

\author{
Ruijiong Gao, ${ }^{1, *}$ \\ ${ }^{1}$ Yuci Longhu School, Jinzhong, 030600, People's Republic of China \\ ${ }^{*}$ Corresponding author. Email: guanghua.ren@gecacdemy.cn
}

\begin{abstract}
As a kind of ecosystem, the composition of the commercial ecosystem must be intertwined with each other, just as the natural ecosystem can extend to the natural environment of the outer planet and can be subdivided into a specific chemical element. The commercial ecosystem is endless. Understanding the correct composition of the business ecosystem and finding the appropriate ecological niche is conducive to the survival and development of every business person. This paper reviews the viewpoints of the scholars who have studied the business ecosystem in detail, including the concept, structure, and characteristics of the business ecosystem and prospects for the future of the business ecosystem to deepen the research in this field.
\end{abstract}

Keywords: Business ecosystem, Enterprise niche, Enterprise competition

\section{INTRODUCTION}

With the continuous deepening of economic globalization globally, immutable business models and market survival models are disappearing on a large scale. All aspects of business are becoming more interconnected. Operators who want to achieve substantial and stable development must place themselves in A suitable position in the market: externally, it needs to form a dynamic balance among suppliers, intermediaries, customers, and partners; internally, it is necessary to improve the quality and types of services, and the mutual influence between products. For example, Xiaomi Technology Co., Ltd., which has been listed in recent years, is an innovative technology company dedicated to constructing connecting hardware, software, and the Internet ecological chain. It has built the world's largest consumer IoT platform through cooperation with external parties and formed its own business ecosystem. The network is now among the world's top 500 companies. With the continuous changes in the business environment, the improvement and development of the business ecosystem in which the enterprise itself is located are particularly important. This article intends to retrospect the business ecosystem's concept, structure, and characteristics and prospects for future research to deepen the research in this field.

\section{MAIN BODY1}

\subsection{What is the business ecosystem-the proposal of the business ecosystem}

In 1935, ecologist Tansley, A. G. first proposed the concept of "ecosystem" in the "Journal of Ecology" to describe the relationship between various organisms and between biological communities and their inorganic environments within a certain space and time. It is a unified whole that interacts through energy flow and material circulation and maintains a relative balance for a long period afterwards, without too much fluctuation [1]. With the deepening of human understanding of the ecosystem and social organization structure, the concept of "ecosystem" has been introduced into the field of social sciences. In 1993, economist Moore, J. F. published "Predators and prey: a new ecology of competition" in Harvard Business Review, applying the biological ecosystem view to the business field and defining the business ecosystem It is "an economic union and an organism in the business world based on the interaction of organizations and individuals" [2].

\subsection{What is a business ecosystem-a business ecosystem is different from a value network}

Power, T. and Jerjian, G. emphasized the importance of the Internet. The business ecosystem is a worldwide network system that includes a part of the real world that interacts. It is a physical system composed of 
non-biological factors in the environment [3]. At the same time, the business ecosystem is a system composed of entities that need different interests, and these entities exist as a community for their own interests [4]. In Power, T. and Jerjian, G.'s definition of business ecosystems, certain characteristics of natural ecosystems are reflected, indicating that the website is organic, and www is the habitat and virtual residence that many commercial ecosystems rely on. The entire business ecosystem is expressed in the form of an internet site. Geng Shen Zhong and Zhen Zhen Cui believe that the value network is produced by enterprises with the emergence of division of labor and collaboration and develops with the development of the division of labor and collaboration. The full application of modern information technology represented by the Internet in enterprises is the traditional industrial economic era. The value network has achieved significant results in terms of the speed and quality of value creation [5]. David Post, Joseph Martha, and R. Kirk Kramer stated that the concept of this digital supply chain is "a kind of A fast and reliable system that is connected to and driven by new optional devices." This value network model based on Internet technology has five characteristics: Customer-aligned, Collaborative and systemic, Agile and scalable, Fast flow, and Digital [6]. Compared with the value network emphasizing the cocreation of value and the coevolution of the system members, the business ecosystem also emphasizes the system's constraints on the components of the system [7].

\subsection{What is the business ecosystem-the business ecosystem has no center and boundary}

H Håkansson and Snehota, I. pointed out that the business ecosystem does not have a clear center and boundary. Each business ecosystem contains many small business ecosystems. At the same time, it is part of a larger business ecosystem. That is, its boundaries can be based on actual conditions. The definition is free, and a certain company may exist in multiple business ecosystems at the same time [8]. In terms of industrial integration, Porter, M. E. pointed out that the geographical concentration of the industry and the vertical or horizontal interconnection between enterprises form clusters. That is, an industrial cluster is a group of related companies and related institutions that are geographically close to each other [9], such as the Detroit automotive industry cluster in the United States, the Toyota automotive industry cluster in Japan, the Silicon Valley high-tech industry cluster in the United States, the semiconductor industry cluster in Japan, the biomedical industry cluster in London in the United Kingdom, etc.. The business ecosystem has no clear center or clear boundary concept [8]. For example, the business ecosystem of the Haier Group, an ecological brand of the Internet of Things, has established R\&D centers, industrial parks, manufacturing centers, and sales centers in more than 30 countries around the world, and built a localized sales network; as a rising star, Xiaomi Technology Co., Ltd. has established The world's largest consumer IoT platform has been built, and it has entered more than 100 countries and regions around the world. Geng Shen Zhong and Zhen Zhen Cui said that from the perspective of business ecosystems, it is more in line with the characteristics of modern business and more conducive to the improvement of modern enterprises than from the perspective of value networks and clusters [5].

\section{MAIN BODY2}

\subsection{The form of the business ecosystem-the structure of the business ecosystem}

Table 1. Contrast of theories [10, 11]

\begin{tabular}{|c|c|c|}
\hline & Moore, J. F. & Garnsey $E$ and Leong $Y$ \\
\hline $\begin{array}{l}\text { Core } \\
\text { ecosystem }\end{array}$ & $\begin{array}{l}\text { Direct suppliers, } \\
\text { production } \\
\text { companies, sales } \\
\text { channels, and } \\
\text { customers }\end{array}$ & $\begin{array}{l}\text { Investment institutions, } \\
\text { suppliers, } \\
\text { subcontractors, } \\
\text { research institutions, } \\
\text { labor markets, } \\
\text { regulatory agencies, }\end{array}$ \\
\hline $\begin{array}{l}\text { Support } \\
\text { system }\end{array}$ & $\begin{array}{l}\text { Investors, } \\
\text { government } \\
\text { departments, and } \\
\text { universities, research } \\
\text { institutions, and } \\
\text { associations } \\
\text { representing and } \\
\text { consumers } \\
\text { suppliers }\end{array}$ & $\begin{array}{l}\text { and complements are } \\
\text { aimed at enterprises; } \\
\text { Enterprises are aimed } \\
\text { at distributors; } \\
\text { Enterprises and } \\
\text { competitors are aimed } \\
\text { at intermediate } \\
\text { customers, distributors, } \\
\text { and Competitors aim at } \\
\text { the concent f the final }\end{array}$ \\
\hline $\begin{array}{l}\text { Competition } \\
\text { system }\end{array}$ & $\begin{array}{l}\text { Direct competitors } \\
\text { and indirect } \\
\text { competitors }\end{array}$ & $\begin{array}{l}\text { customer's corporate } \\
\text { transaction } \\
\text { environment. }\end{array}$ \\
\hline $\begin{array}{l}\text { Social and } \\
\text { natural } \\
\text { environment } \\
\text { system }\end{array}$ & $\begin{array}{l}\text { The political } \\
\text { environment, } \\
\text { economic } \\
\text { environment, social } \\
\text { environment, } \\
\text { technological } \\
\text { environment, etc. }\end{array}$ & \\
\hline
\end{tabular}


In 1996, Moore, J. F. pointed out that the business ecosystem developed based on the natural ecosystem model transcended the boundaries of enterprises and industries: An overall system development model for the win-win of the member companies within the system, the business ecosystem can be a collection of internal business activities within the enterprise, or it can be a consortium of enterprises. And expanded his own views in 1993, further clarified the structure of the business ecosystem and systematically explained the concept of the business ecosystem: a business ecosystem is "risk-takers, financial institutions, trade groups, trade unions, governments, social public service agencies, and other reasons related parties have a dynamic structure system composed of organizations or groups with a certain interest relationship"; further clarified the evolution mechanism of the business ecosystem, indicating that the business system is divided into "Four periods of "generation, development, leadership, and self-renewal or extinction"; pointed out that the business ecosystem can be divided into a core ecosystem that includes direct suppliers, production companies, sales channels, and customers, support system that including investors, government departments, and universities, research institutions, and associations representing consumers and suppliers, including the competition system of direct competitors and indirect competitors, as well as the "social and natural environment system" including political environment, economic environment, social environment, technological environment, etc." [10]. Garnsey E and Leong Y proposed that investment institutions, suppliers, subcontractors, research institutions, labor markets, regulatory agencies, and complements are aimed at enterprises, enterprises are aimed at distributors, and enterprises and competitors are aimed at intermediate customers, distributors and Competitors aim at the concept of the final customer's corporate transaction environment [12]. Compared with Moore, J. F.'s theory, Garnsey E and Leong Y also analyzed competitors' customers.

In 1996, Lu Ling put forward the concept of enterprise ecosystem, indicating that the enterprise ecosystem is the unity of the survival environment of the enterprise and the enterprise, and also put forward the theory of enterprise ecology, indicating that enterprise ecology is the science of the relationship between the enterprise and its environment [13].

Peltoniemi, M. and Vuori, E. pointed out that the business ecosystem is a flexible and dynamic structural system composed of organizations with certain relationships. The constituent organization may be any organization that may affect the entire system, such as enterprises, universities, research institutions, social public service institutions [14]. A niche refers to the sum of resource utilization and environmental adaptability of a biological unit [13]. Both Lewin, R.and Iansiti, $\mathrm{M}$. and Levien, $\mathrm{R}$ pointed out that the business ecosystem is promoted by companies occupying different niches but related to each other. The change of one of them will cause the other to change $[15,16]$. Iansiti, M.and Levien, R, based on the company's niche and corporate strategy in the business ecosystem, divided the company into "Keystone enterprises that maintaining the health of the ecosystem by influencing specific behaviors in this system and acting as the regulator of the business ecosystem", "Dominators enterprises that manage and control most important nodes in the business ecosystem through vertical or horizontal integration", and "Niche players enterprises that concentrate their ability to distinguish themselves from other enterprises on certain businesses and use them, with key resources provided by other companies to carry out business activities", and indicates that the corporate strategy does not regard the business network as a combination of traditional supply chain partners, but an organic ecosystem. It has become a communication between two business ecosystems, and attention should be paid to the overall characteristics of the business network in which they participate. He also stated that almost all healthy ecosystems could be reflected by specific functions performed by certain types of core enterprises [16].

\subsection{The form of the business ecosystem-the characteristics of the business ecosystem}

James M. Tian pointed out that the business ecosystem has the characteristics of co-evolution, integration, niche, self-organization, periodicity and evolution, and openness, which are highly similar to natural ecosystems [17]. Ecosystems, human brains, and global economic systems are all complex adaptive systems [18]. In 2003, Mitleton-Kelly, E. pointed out that complex adaptive systems have ten basic characteristics: Coevolution, Exploration-of-the-space-of-possibilities, Historicity, Far from equilibrium, Feedback, Path-dependency, Association Connectivity, Interdependence, Emergence, Self-organization [19]. Peltoniemi, M. and Vuori, E. applied the complex adaptive system to the business ecosystem and pointed out that the business ecosystem has four basic characteristics: emergence, co-evolution, adaptability, and self-organization [14]. Subsequently, they proposed that the business ecosystem is aimed at innovation and business success, conscious choice, dynamics, affected by environmental changes, numerous participants, interdependence, interaction, competition and cooperation, and a common destiny [20]. 


\subsection{The form of the business ecosystem-the analysis model of the business ecosystem}

In 1996, Moore, J. F. proposed the 4P3S seven-dimensional analysis framework, which analyzes the seven aspects of people, place, product, process, structure, shareowner, and social environment. This is the earliest business ecosystem analysis framework [10]. Later, many scholars put forward their own opinions. For example, Anggraeni, E. et al. proposed to study the characteristics of the business ecosystem from six aspects: corporate characteristics, corporate roles, network structure, network dynamics, network performance, and network governance [21]; Tian Et al. proposed a business ecosystem model which mainly includes seven elements of resources, activities, decisions, standards, roles, business entities and business models [22]. Adam M. Brandenburger and Barry J. Nalebu, in "A Revolutionary Mindset That Redefines Competition and Cooperation; the Game Theory Strategy That's Changing the Game of Business", analyzed the cooperation of enterprises from the perspective of the game and the three points to be considered in the competition, namely Value Net, PARTS, Role-Playing [23].

In 2002, Iansiti, M. and Levien, R were the first to propose "the productivity that reflects the effectiveness of the business ecosystem's transformation of innovation into a new product or service", "measures the robustness of the business ecosystem's ability to respond to environmental disturbances" and "Niche creativity", The three dimensions of "niche creativity to create new valuable niche markets for the business ecosystem" and "niche creativity" are used to measure the health of the business ecosystem. Among them, productivity is analyzed from three aspects: productivity, productivity improvement, and the realization of innovation; robustness is analyzed from five aspects: survival, sustainability, predictability, moderate elimination, and sustainability; niche creativity is analyzed from diversity and Analysis of two aspects of value creation. In general, Iansiti, M. and Levien, R's evaluation index system for the health of the business ecosystem must obtain data from companies [24]. Hartigh, E. D. et al. appropriately adjusted the measurement indicators prescribed by Iansiti, M. and Levien, $\mathrm{R}$ to shift productivity from asset accumulation and Network resources are analyzed from two aspects. The robustness is analyzed from the four aspects of bankruptcy, liquidity, connectivity, and centrality. The niche creativity is analyzed from the two aspects of diversity and solvency. Return on assets, ratio of current assets, solvency, and total asset growth rate analysis of the five aspects of partner health and network health from the three aspects of the number of partnerships, market predictability, and partner diversity [25], ascending to the entire system is more advantageous for evaluating the health of the business ecosystem.

\subsection{The form of the business ecosystem-the analysis model of the business ecosystem}

Hartigh, E. D. et al. stated that the business ecosystem is a network system composed of suppliers and customers gathered due to a certain core technology [25]. In contrast, Zahra, S. A. and Nambisan, S. stated that the business ecosystem network is based on the long-term relationship between member companies, the formation of interactive relationships and the construction and development of a business ecosystem requires the matching of entrepreneurial insight and strategic thinking [26]. The ecological business system itself is a complex adaptive system. As long as different factors are mixed, there will be different conclusions. Many scholars have interpreted all aspects of the ecological business system. Some focused on the overall characteristics of the business ecosystem, some focused on the external connections of the business ecosystem, some focused on the internal structure of the business ecosystem, and some focused on the actual value of the business ecosystem. Even in the same aspect, there will be different interpretations.

\subsection{The form of the business ecosystem -- the core competitiveness of enterprises in the business ecosystem}

Core Competence is an important aspect to achieve and maintain competitive advantage [27]. In 1990, Prahal Ad, C. K., and Hamel Gary first proposed The concept of Core Competence in "The Core Competence of Corporation", published in Harvard Business Review. Core competitiveness can provide a potential way for an enterprise to share a wide and diversified market and make the final product bring important value to customers. Core competitiveness refers to the collective knowledge in an organization, especially how to coordinate and integrate various technologies, which is difficult for competitors to imitate [28]. Snyder, A. V. et al. pointed out that core competitiveness refers to value-added activities that can be carried out at A lower cost than their competitors [29]. Mark, R. et al. pointed out that core competitiveness is a synergy of organizational competitiveness embodied in basic capabilities of functional departments, key capabilities of SBU, and coordination capabilities at the company level [30]. Coombs R. et al. pointed out that core competition is a specific combination of enterprise capabilities and the accumulation of specific experience that enables enterprises, markets, and technologies to interact [31]. Kevin P.Covne et al. pointed out that core competitiveness is a solid set of skills and knowledge that complement each other in a group [32]. 


\section{CONCLUSION}

Since the business ecosystem concept has been put forward, it has experienced decades of development, but most scholars still believe that today's business ecosystem is still immature. The business ecosystem, that is, the ecosystem in the business field, has only changed the target object compared to the natural ecosystem, and the nature of the ecosystem cannot be changed. Just like in ecology, from the biologist Charles Robert Darwin's proposal that "nature is the interaction between species and their living environment", to naturalist Ernst Haeckel's naming of this view "ecology", to botany Eugen Warming incorporates non-biological physical factors such as landscape and climate into ecology, to ecologist Tansley, A. G.'s concept of "ecosystem", and continue to include the development of terrestrial ecosystems, aquatic ecosystems, artificial ecosystems, production systems, These ecosystems are further subdivided into biological communities, time structures, nutrient structures, and material cycles, among which there are endless branches. Even to be subdivided into a specific chemical element.

\section{Existing problems:}

First of all, the research of the business ecosystem is still in the stage of continuous expansion of the involved fields and data, and a complete research system has not been formed; second, because the business ecosystem has not yet formed a complete research system, the actual operation of the business system is more involved. Therefore, it stays at the theoretical level, and the concept of a business system has not been popularized.

\section{Suggest:}

First, integrate theories of other fields and conduct in-depth and broad research. Just as the integration mentioned above of natural ecosystems with other domain theories has elevated itself to a stage of basic perfection, commercial ecosystems, as metaphors and branches of ecosystems, should refer to the integrated parts of natural ecosystems to find the corresponding ones in business factors for further development, it has been verified such as the biological community corresponds to different types of enterprises, the succession of enterprises corresponding to the time structure, the cooperation and mergers of enterprises corresponding to the nutritional structure, the transactions of enterprises corresponding to the material cycle, and the continuous subdivision into a certain natural ecosystem. A certain dialogue between the enterprise corresponding to the chemical element and the enterprise. At the same time, we should also pay attention to the "protection and utilization", "regulation mechanism research", "degradation mechanism, restoration, and restoration research", "global problem research", and "sustainable development research" corresponding to the business ecosystem". The business ecosystem has undergone a transformation from conceptual research to system internal structure research, cross-system research, and theoretical research to practical research. It has evolved from vertical integration, internal capabilities, internal $R \& D$, internal projects, and internal infrastructure and towards a situation of interdependence, decentralized innovation, technological integration, voluntary collaboration, and the ability to respond to demand.

Companies of all types should follow the logic of the "food chain": "niche separation", that is, when two organisms use the same resource or share an environmental variable, there will be overlapping niches, leading to competition. The business ecosystem is based on the separation of corporate niches. Various types of organisms in the ecosystem play an important role in the environment. By feeding between species and between organisms and the environment, nature has formed multiple complete food chains and constituted a complex food web. A virtuous cycle of material flow and energy transmission in the ecosystem is being carried out on the web. In the business ecosystem, diversity plays a buffering role in each key ecological niche, and the protection of diversity in the system is an important measure. In particular, keystone companies should actively expand their own technological fields, try to avoid other competition take for their own ecological niches, and being in a monopoly position. In addition, there is no need to specifically propose some small branches for the future research directions or research aspects of the business ecosystem. Everything has a history in the mother body of the natural ecosystem.

Second, while calling for more scholars to participate in the study of broadening the business ecosystem, it also calls on more writers to summarize the views expressed by many scholars. The innovation of a theory is important, but the summary of innovation is also important. It can show the development process of the current business ecosystem and allow more scholars who want to study the business ecosystem in the future to provide innovations needed. Inspiration and direction will eventually reach the point where it is basically complete like the natural ecosystem. They will eventually popularize the concept and practical operation of the business ecosystem to every corner of the business so that the entire business world can develop more healthily and steadily.

\section{REFERENCES}

[1] Tansley, A. G. . (1935). The use and abuse of vegetational concepts and terms. Ecology, 16(3). 
[2] Moore, J. F. . (1993). Predators and prey: a new ecology of competition. Harvard business review, págs. 75-83.

[3] Power, T. , \& Jerjian, G. . (2001). Ecosystem: Living the 12 principles of networked business.

[4] Corallo, A. , Passiante, G. , \& Prencipe, A. . (2007). The digital business ecosystem $\|$. , $10.4337 / 9781781009925$.

[5] Geng Shen Zhong, \& Zhen Zhen Cui. (2009). Business ecosystem theory and its development direction. Dongyue Cong, 30(006), 27-33.

[6] David Bovet, Joseph Martha, R. Kirk Kramer, David Bovet, Joseph Martha \& R. Kirk Kramer. (2001). Value net. Posts and Telecommunications Press.

[7] (2001). Business as a living system: the value of industrial ecology. California Management Review.

[8] H Håkansson, \& Snehota, I. . (1995). Developing relationships in business networks. Routledge.

[9] Porter, M. E. . (2009). The Competitive Advantage of Nations, States and Regions.

[10] Moore, J. F. . (1996). The death of competition: leadership \& strategy in the age of business. Ecosystems.

[11] (2001). Business as a living system: the value of industrial ecology. California Management Review.

[12] Garnsey, E. , \& Leong, Y. Y. . (2008). Combining resource-based and evolutionary theory to explain the genesis of bio-networks. Industry \& Innovation, 15(6), 669-686.

[13] Lu Ling. (1996). On the principle of enterprise ecology. Science in the World, 03, 44-46.

[14] Peltoniemi, M. , \& Vuori, E. . (2004). Business ecosystem as the new approach to complex adaptive business environments. Proceedings of eBusiness research forum.

[15] Lewin, R. . (1993). Complexity: life at the edge of chaos. American Journal of Physics, 61(8), L627-L633(7).

[16] Iansiti, M. , Levien, R. , Iansiti, M. , \& Levien, R. . (2004). The keystone advantage: what the new dynamics of business ecosystems mean for strategy, innovation, and sustainability. Future Survey, 20(2), 88-90.

[17] James M. Tian. (1997). The Road to Survival: A new management revolution triggered by computer technology. Tsinghua University Press.
[18] Taylor, L. R. , Real, L. A. , \& Brown, J. H. . (1991). Foundations of ecology. Journal of Animal Ecology, 61(3), 801.

[19] Mitleton-Kelly, E. . (2003). Ten principles of complexity and enabling infrastructures.

[20] Peltoniemi, M. , Vuori, E. , \& Laihonen, H. . (2005). Business ecosystem as a tool for the conceptualisation of the external diversity of an organisation.

[21] Anggraeni, E. , Hartigh, E. D. , \& Zegveld, M. . (2007). Business ecosystem as a perspective for studying the relations between firms and their business networks.

[22] Tian, C., H. , Ray, B., K. , Lee, \& J., et al. (2008). Beam: a framework for business ecosystem analysis and modeling. IBM Systems Journal.

[23] CoOpetition . A Revolutionary Mindset That Redefines Competition and Cooperation. (1997). Co-Opetition: 1. A Revolutionary Mindset That Redefines Competition and Cooperation; 2. the Game Theory Strategy That's Changing the Game of Business. Currency Doubleday.

[24] Iansiti, R. M. . (2002). Keystones and Dominators: Framing the Operational Dynamics of Business Ecosystems.

[25] Hartigh, E. D. , Tol, M. , \& Visscher, W. . (2006). The Health Measurement of a Business Ecosystem.

[26] Zahra, S. A. , \& Nambisan, S. . (2012). Entrepreneurship and strategic thinking in business ecosystems. Business Horizons, 55(3), 219-229.

[27] FredRDavid. (2001). Strategic Management: Concepts and Cases. Tsinghua University Press.

[28] Prahal Ad , C. K. , \& Hamel, G. . (2000). The core competence of the corporation *. Strategic Learning in a Knowledge Economy(3), 3-22.

[29] Snyder, A. V. , \& Ebeling, H. W. . (1992). Targeting a company's real core competencies. Journal of Business Strategy, 13(6), 26.

[30] Mark, R., Gallon, Harold, M., \& Stillman, et al. (1995). Putting core competency thinking into practice. Research Technology Management.

[31] Coombs, R. . (2010). Core competencies and the strategic management of $r \& d . ~ R \& D$ Management, 26(4), 345-355.

[32] Kevin P.Covne, Stephen J.D.Hall, \& Patricia Gorman Clifford. (2001). The core competitiveness of either true or unreal. Chinese Entrepreneur, 000(009), 86-89. 